\title{
REVIEW
}

\section{Treatments Administered to the First 9152 Reported Cases of COVID-19: A Systematic Review}

\author{
David C. Fajgenbaum (D) · Johnson S. Khor • Alexander Gorzewski • \\ Mark-Avery Tamakloe · Victoria Powers · Joseph J. Kakkis • \\ Mileva Repasky · Anne Taylor · Alexander Beschloss · Laura Hernandez-Miyares • \\ Beatrice Go · Vivek Nimgaonkar · Madison S. McCarthy • \\ Casey J. Kim · Ruth-Anne Langan Pai · Sarah Frankl · Philip Angelides • \\ Joanna Jiang · Rozena Rasheed · Erin Napier · Duncan Mackay • \\ Sheila K. Pierson
}

Received: April 24, 2020 / Published online: May 27, 2020

(C) The Author(s) 2020

\section{ABSTRACT}

The emergence of SARS-CoV-2/2019 novel coronavirus (COVID-19) has created a global pan-

David C. Fajgenbaum and Johnson S. Khor contributed equally to this study.

Digital Features To view digital features for this article go to https://doi.org/10.6084/m9.figshare.12287996.

Electronic supplementary material The online version of this article (https://doi.org/10.1007/s40121020-00303-8) contains supplementary material, which is available to authorized users.

D. C. Fajgenbaum $(\bowtie) \cdot$ J. S. Khor · A. Gorzewski · M.-A. Tamakloe · V. Powers · R.-A. L. Pai ·

R. Rasheed · S. K. Pierson

Department of Medicine, Division of Translational Medicine and Human Genetics, Perelman School of Medicine, University of Pennsylvania, Philadelphia, PA, USA

e-mail: davidfa@pennmedicine.upenn.edu

A. Beschloss · L. Hernandez-Miyares · B. Go ·

V. Nimgaonkar · C. J. Kim · S. Frankl · P. Angelides · J. Jiang

Perelman School of Medicine, University of

Pennsylvania, Philadelphia, PA, USA

J. J. Kakkis

University of Pennsylvania, Philadelphia, PA, USA

M. S. McCarthy

Brown University, Providence, RI, USA demic with no approved treatments or vaccines. Many treatments have already been administered to COVID-19 patients but have not been systematically evaluated. We performed a systematic literature review to identify all treatments reported to be administered to COVID-19 patients and to assess time to clinically meaningful response for treatments with sufficient data. We searched PubMed, BioRxiv, MedRxiv, and ChinaXiv for articles reporting treatments for COVID-19 patients published between 1 December 2019 and 27 March 2020. Data were analyzed descriptively. Of the 2706 articles identified, 155 studies met the inclusion criteria, comprising 9152 patients. The cohort was $45.4 \%$ female and $98.3 \%$ hospitalized,

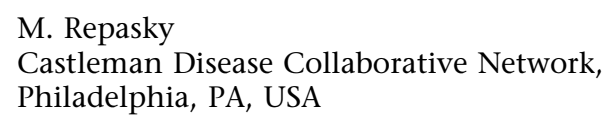

A. Taylor

The Ohio State University College of Medicine, Columbus, OH, USA

E. Napier John A. Burns School of Medicine, University of Hawaii, Honolulu, HI, USA

D. Mackay

Department of Surgery, Perelman School of Medicine, University of Pennsylvania, Philadelphia, PA, USA 
and mean (SD) age was 44.4 years (SD 21.0). The most frequently administered drug classes were antivirals, antibiotics, and corticosteroids, and of the 115 reported drugs, the most frequently administered was combination lopinavir/ritonavir, which was associated with a time to clinically meaningful response (complete symptom resolution or hospital discharge) of 11.7 (1.09) days. There were insufficient data to compare across treatments. Many treatments have been administered to the first 9152 reported cases of COVID19. These data serve as the basis for an open-source registry of all reported treatments given to COVID-19 patients at www.CDCN.org/ CORONA. Further work is needed to prioritize drugs for investigation in well-controlled clinical trials and treatment protocols.

Keywords: COVID-19; Drug repurposing; SARS-CoV-2; Systematic literature review

\section{Key Summary Points}

\section{Why carry out this study?}

Data on drugs that have been used to treat COVID-19 worldwide are currently spread throughout disparate publications.

We performed a systematic review of the literature to identify drugs that have been tried in COVID-19 patients and to explore clinically meaningful response time.

\section{What was learned from the study?}

We identified 115 uniquely referenced treatments administered to COVID-19 patients. Antivirals were the most frequently administered class; combination lopinavir/ritonavir was the most frequently used treatment.

This study presents the latest status of offlabel and experimental treatments for COVID-19. Studies such as this are important for all diseases, especially those that do not currently have definitive evidence from randomized controlled trials or approved therapies.

\section{INTRODUCTION}

SARS-CoV-2 as well as its related disease, 2019 novel coronavirus (COVID-19), is a global pandemic. Over 2,200,000 cases and 150,000 deaths have been reported to date worldwide [1]. With an $\mathrm{R}_{0}$ reportedly as high as $2-2.5$ and a significant case fatality rate, this virus will continue to have a major impact on the health and wellbeing of humans worldwide.

COVID-19 patients exhibit a highly heterogeneous clinical course from mild flu-like symptoms to cytokine-storm-driven acute respiratory and multi-organ failure [2]. Physicians worldwide have administered numerous treatments off-label and through clinical trials to treat COVID-19 patients. Although only four months have elapsed since the emergence of COVID-19, many case reports, single-center series, and interventional studies have been published in medical journals as well as pre-publication archives. Some of these treatments have received widespread attention and are currently undergoing randomized controlled trials while others have not. Identifying and inventorying the full range of treatments reported in use is critical for physicians treating COVID-19. Further indicators of effectiveness among those treatments are important for governments, public health organizations, and pharmaceutical companies identifying and prioritizing treatments for wellcontrolled clinical trials [3]. However, a systematic effort to consolidate and centralize all treatment data is missing.

Our objective was to perform a systematic review to inventory all treatments that have been reported through any study design to be given to COVID-19 patients and to investigate the time to clinically meaningful response among the most frequently administered treatments when sufficient data were available.

\section{METHODS}

\section{Search Strategy and Selection Criteria}

We completed our systematic literature review according to the PRISMA guidelines 
(Supplementary Table 1) [4]. We searched PubMed, BioRxiv, MedRxiv, and ChinaXiv from December 1, 2019, to March 27, 2020, using the following terms "COVID19" OR "SARS-CoV-2" OR "2019-nCoV". The search was not restricted to publications in any language as translation tools were used for articles not written in English. However, 22 articles could not be accessed, translated, or interpreted by the extractor. Additional references were identified through bibliography searches and review of articles written by study authors. Inclusion criteria included all studies reporting the use of any treatments in COVID-19 patients. Reasons for exclusion include duplication and lack of information on drug treatments administered to COVID-19 patients. No studies were excluded based on participants, treatments, outcomes, study design, or length of study. Both patientand summary-level studies were included. Given the urgency and importance of this information, articles deposited into online prepublication archives were also included. The full text of all articles was reviewed by at least one data extractor to determine if the paper met the inclusion and exclusion criteria. A review protocol can be accessed at https://www.cden. org/CORONA.

\section{Data Extraction}

All articles meeting inclusion criteria were read and extracted into a centralized spreadsheet. Elements collected included article type, nationality of the authors, patient disease characteristics, treatments administered, and outcomes, when available. A second individual, either holding a medical degree or currently in medical school, performed an independent review of every article and repeated data extraction for every data point. A third individual (JSK) resolved discrepancies between the two extractors. JSK also reviewed the article list and data extractions to remove duplicates and resolve discrepancies related to study inclusion. Data on all patients with drug treatment information available were included to avoid selective reporting bias within studies, but publication bias is likely present in this study.
Data extraction fields are listed in Supplementary Table 2.

\section{Data Analysis}

Data were analyzed descriptively; no hypothesis tests were performed. Frequency counts and percentages were used to describe categorical data. A weighted mean (standard deviation) was tabulated for continuous data (age, C-reactive protein, time to clinically meaningful response). For summary-level studies that presented continuous data using a median and interquartile range or sample range, sample mean and standard deviation were imputed using the Wan et al. method [5]. Data were combined, and an inverse-variance weighted mean was calculated for age and time to clinically meaningful response (TCMR). TCMR was calculated when available at a per-patient and per-drug level and was defined as the shortest duration between drug start and full symptom resolution (according to author) or hospital discharge. When data on both of these time points were provided, the shortest duration was considered as the TCMR. TCMR cannot be conclusively attributed to a given drug, as drugs were included in the calculation regardless of whether they were used alone, concurrently, or sequentially. For the Kaplan-Meier analysis, patients who were not reported to achieve our definition of clinically meaningful response were censored at time to improvement. Treatments were classified according to the Anatomical Therapeutic Classification (ATC) therapeutic subgroup. Analyses were performed using $\mathrm{R}$ (version 3.6.0). This article is based on previously conducted studies and does not contain any studies with human participants or animals performed by any of the authors.

\section{RESULTS}

We identified and reviewed 2706 papers (PubMed: 1795, Biorxiv: 298, Medrxiv: 591, Chinaxiv: 22). Of those, 2542 were excluded and 164 underwent complete data extraction by two independent extractors (Fig. 1). The studies varied in category from single case reports in 


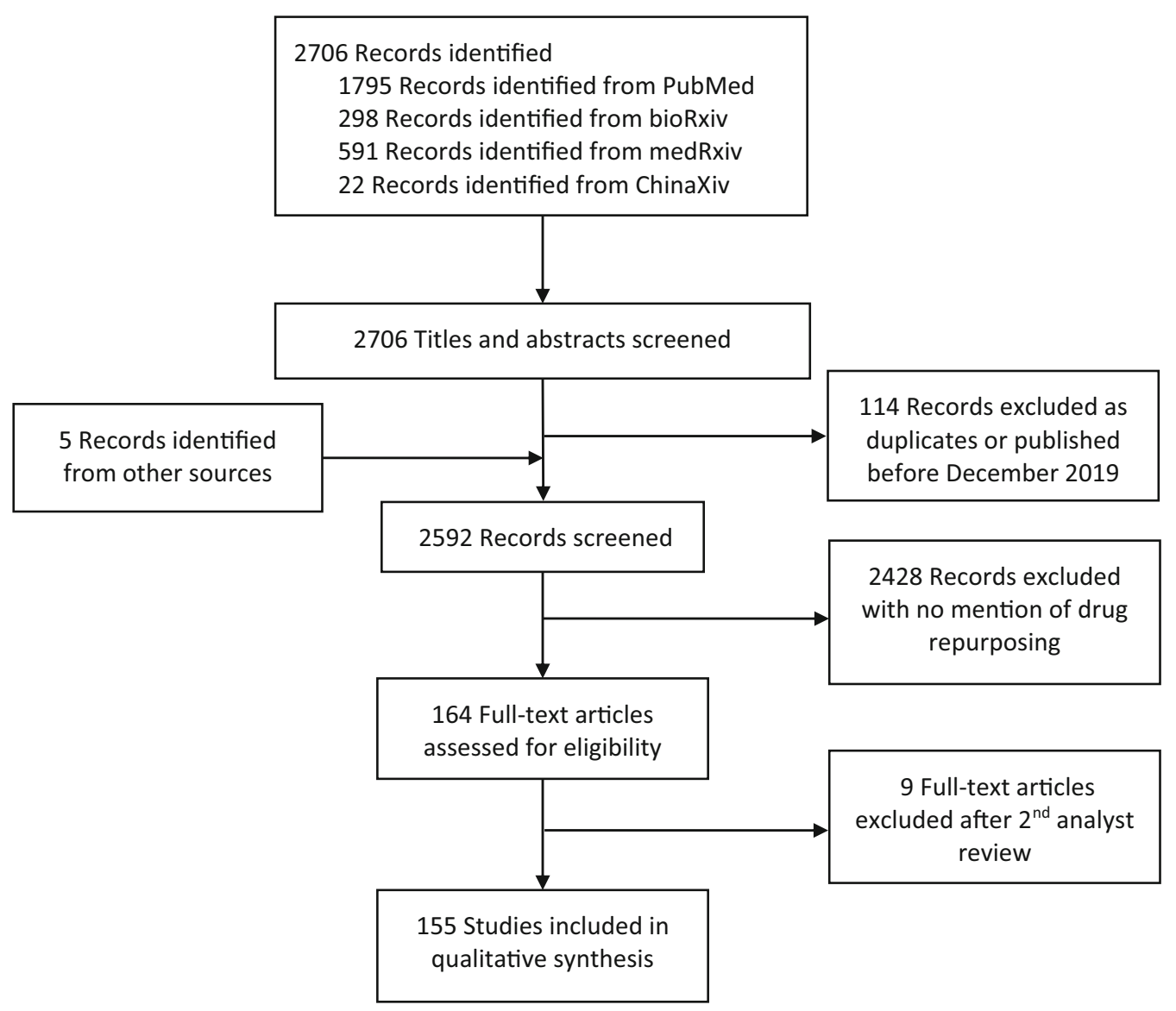

Fig. 1 PRISMA study selection

pre-publication archives to published randomized controlled trials. There were 155 studies that satisfied inclusion criteria, with 130/155 (83.9\%) reported from China and 25 (16.1\%) reported from 13 other countries (Afghanistan, France, Germany, Italy, Japan, Korea, Scotland, Singapore, Spain, Taiwan, UK, the USA, and Vietnam). Nine articles were determined not to meet inclusion criteria when re-reviewed by a second extractor. Of the 155 studies, 117 were published in journals indexed on PubMed; the remainder were published in online archives. Studies reviewed included 87 single-patient retrospective case reports, 65 retrospective case series of between 2 and 1099 cases, and 3 interventional clinical trials. Data for 9152 patients were reported, with data reported from 238 patients on an individual patient-level and 8914 patients on a summary level. These data are available in Supplementary Table 3, and an updated COvid-19 Registry of Off-label \& New Agents (CORONA) can be accessed at https:// www.cdcn.org/CORONA.

Patients included in the analysis are predominantly Chinese (98.4\%) (Table 1). The weighted mean patient age was 44.4 (SD 21.0) years, and $45.4 \%$ of patients were female. The method of positive COVID-19 testing was reported for $91.3 \%$ of patients included in the analysis. Nearly all cases were reported to be hospitalized (98.3\%), and 1672 (18.3\%) were reported to require ventilation. In $2470(27.0 \%)$ cases, the author described the patient(s) as having "severe" disease.

All patients included in this analysis received at least one treatment intended to treat COVID19 (Table 1, Supplementary Table 3). Fourteen therapeutic categories comprised a total of 115 reported treatments as well as many non-descript treatments (e.g., "antibiotics not 
Table 1 Study populations

\begin{tabular}{|c|c|}
\hline$N$ & 9152 \\
\hline \multicolumn{2}{|l|}{ Age (years) } \\
\hline Mean (SD) & $44.4(21.0)$ \\
\hline Not reported/unknown & 281 \\
\hline \multicolumn{2}{|l|}{ Sex } \\
\hline Female & $4155(45.4)$ \\
\hline Male & $4993(54.6)$ \\
\hline Not reported/unknown & 4 \\
\hline \multicolumn{2}{|l|}{ Country of publication } \\
\hline China & $9002(98.4)$ \\
\hline France & $101(1.1)$ \\
\hline Singapore & $19(0.2)$ \\
\hline USA & $9(0.1)$ \\
\hline Taiwan & $6(0.1)$ \\
\hline Korea & $3(0.03)$ \\
\hline Germany & $2(0.02)$ \\
\hline Italy & $2(0.02)$ \\
\hline UK & $2(0.02)$ \\
\hline Vietnam & $2(0.02)$ \\
\hline Afghanistan & $1(0.02)$ \\
\hline Japan & $1(0.01)$ \\
\hline Scotland & $1(0.01)$ \\
\hline Spain & $1(0.01)$ \\
\hline \multicolumn{2}{|l|}{ COVID-19 testing } \\
\hline Testing method reported & $8357(91.3)$ \\
\hline Testing method not reported & $795(8.6)$ \\
\hline \multicolumn{2}{|l|}{ Hospitalized } \\
\hline Yes & 8997 (98.3) \\
\hline No & $143(1.6)$ \\
\hline Not reported & $12(.1)$ \\
\hline \multicolumn{2}{|l|}{ ICU stay required } \\
\hline Yes & $1017(11.1)$ \\
\hline No & $4112(44.9)$ \\
\hline
\end{tabular}

Table 1 continued

\begin{tabular}{lc}
\hline Not reported & $4023(44.0)$. \\
Ventilator required & $1672(18.3)$ \\
Yes & $5564(60.8)$ \\
No & $1916(20.9)$ \\
Not reported & \\
Author-defined severity & $2470(27.0)$ \\
Severe & $5031(55.0)$ \\
Not severe & $1651(18.0)$ \\
Not reported & \\
\hline
\end{tabular}

Data are mean $(\mathrm{SD})$ or $n / N(\%)$, unless otherwise specified

otherwise specified"). Treatments described were administered alone, concurrently, or sequentially with others. Given the nature of the reports, we did not differentiate concurrent or sequential treatment regimens. The most frequently administered classifications of treatments were antivirals $(N=6547,71.5 \%)$, antibiotics $(N=4263,46.6 \%)$, and corticosteroids $(N=2392,26.1 \%)$ (Fig. 2a). The most frequently administered treatment given to all patients was combination lopinavir/ritonavir $(N=2000,21.9 \%)$, followed by interferon $\alpha / \beta$ $(N=1767, \quad 19.3 \%) \quad$ and immunoglobulins $(N=1049, \quad 11.5 \%) \quad$ (Fig. 2b, Supplementary Table 4). Of the treatments identified, 100 $(86.9 \%)$ were administered to $<1 \%$ of all patients.

On a per drug basis, response data were sparse and were largely only available on the individual patient level (e.g., case study). Six drugs had patient TCMR data from at least ten patients and at least ten studies. From our review, oseltamivir (ten patients from ten studies) was associated with the longest average TCMR of 19.8 (10.62); however, the sample size was too small to perform statistical comparisons between drugs (Table 2 , Fig. 3). Interferon- $\alpha / \beta$, which had the highest amount of available response data $(N=107$ patients from $N=14$ 

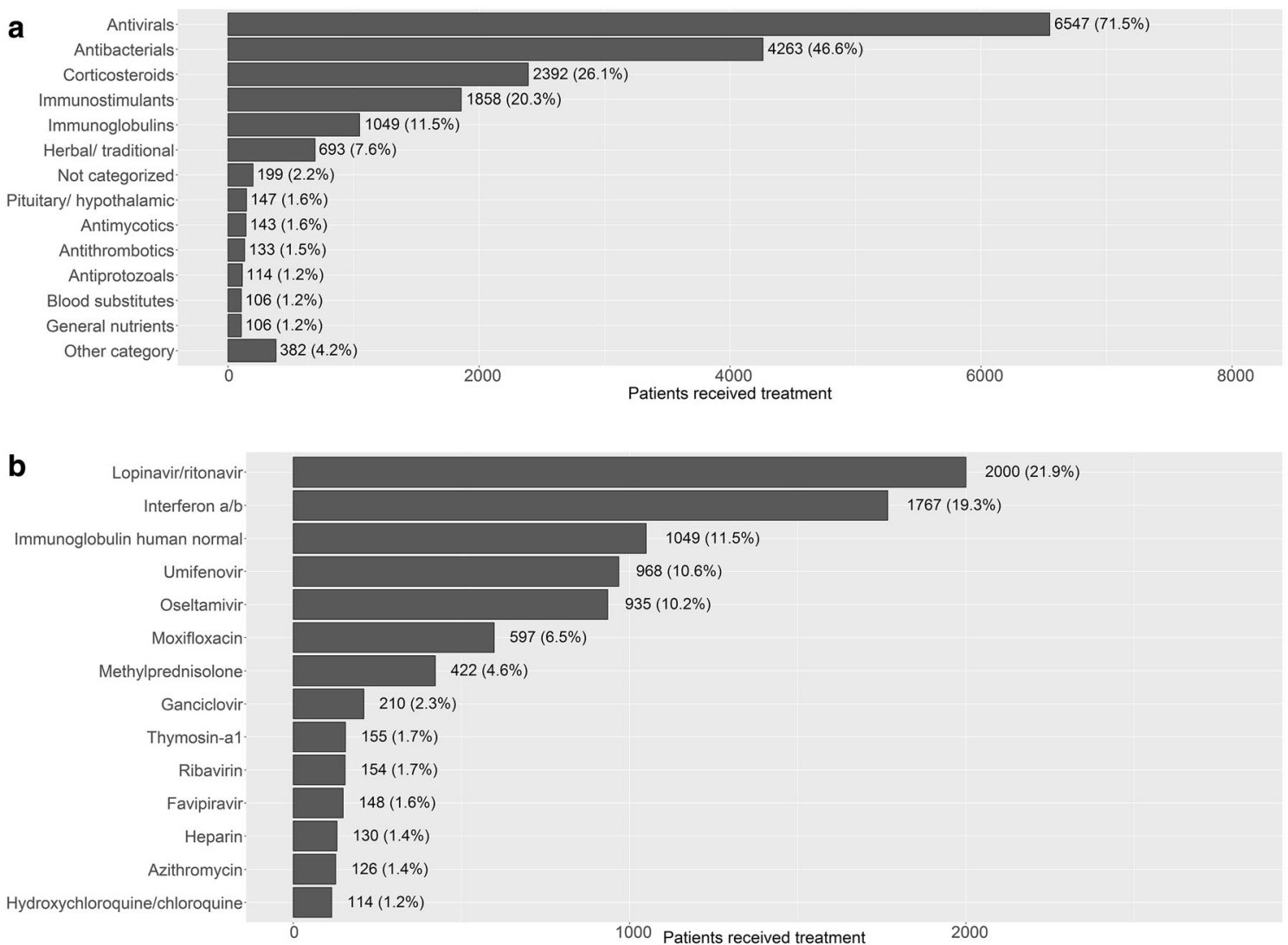

Fig. 2 Most frequently administered therapeutic classes of drugs. Most frequently administered therapeutic classes of drugs according to the Anatomical Therapeutic Classification system (a), and most frequently administered

studies), was associated with the shortest weighted TCMR, at mean (SD) 9.9 (2.65). Combination lopinavir/ritonavir included the second most available data $(N=76$ patients from $N=15$ studies) and was associated with a TCMR of 11.7 (1.09) days. For these two treatments, we restricted to the studies reporting patient-level observations and plotted a KaplanMeier curve for time to clinically meaningful response $(N=37$ observations for interferon- $\alpha / \beta$ and $N=34$ observations for lopinavir/ritonavir) (Supplementary Fig. 1). For both drugs, median TCMR was $<2$ weeks.

We compiled a framework through which several treatments identified in this study may be exerting their effects based on recent insights into COVID-19 pathogenesis (Fig. 4). SARSCoV-2 binds to the ACE2 receptor on ciliated individual drugs reportedly used among the 9152 patients (b)

bronchial epithelial cells to gain entry into these cells for viral replication and dissemination in the airway [6]. Patients with a weakened immune response would be expected to have difficulty controlling COVID-19. Patients with a hyper-immune response experience acute respiratory distress syndrome, septic shock, and multiple organ system failure due to a cytokine storm [7]. Treatments used to date have been proposed to work by inhibiting or modulating these viral or host mechanisms [8-11].

\section{DISCUSSION}

Despite advances in medical care, therapeutics, and infrastructure that have lowered the burden of infectious diseases in recent years, COVID-19 has emerged as a leading cause of death in 
Table 2 Time to clinically meaningful response for patients on the seven most frequently used drugs (independently or in combination with other treatments)

\begin{tabular}{|c|c|c|c|c|c|}
\hline Treatment $(N)$ & $N$ studies & $N$ patients & $\begin{array}{l}\% \text { of patients on drug } \\
\text { extractable TCMR }\end{array}$ & Mean (SD) TCMR & Standard error \\
\hline \multicolumn{6}{|c|}{ Antivirals for systemic use } \\
\hline \multicolumn{6}{|l|}{ Lopinavir/ritonavir } \\
\hline Total & 15 & 76 & $3.8 \%$ & $11.7(1.09)$ & 0.13 \\
\hline Patient-level & 14 & 25 & & & \\
\hline Summary-level & 1 & 51 & & & \\
\hline \multicolumn{6}{|l|}{ Umifenovir } \\
\hline Total & 10 & 13 & $1.3 \%$ & $10.9(7.78)$ & 2.16 \\
\hline Patient-level & 10 & 13 & & & \\
\hline Summary-level & 0 & 0 & & & \\
\hline \multicolumn{6}{|l|}{ Oseltamivir } \\
\hline Total & 10 & 10 & $1.1 \%$ & $19.8(10.62)$ & 3.36 \\
\hline Patient-level & 10 & 10 & & & \\
\hline Summary-level & 0 & 0 & & & \\
\hline \multicolumn{6}{|c|}{ Immunostimulants } \\
\hline \multicolumn{6}{|l|}{ Interferon- $\alpha / \beta$} \\
\hline Total & 14 & 107 & $6.1 \%$ & $9.9(2.65)$ & 0.26 \\
\hline Patient-level & 12 & 32 & & & \\
\hline Summary-level & 2 & 75 & & & \\
\hline \multicolumn{6}{|c|}{ Corticosteroids for systemic use } \\
\hline \multicolumn{6}{|c|}{ Methylprednisolone } \\
\hline Total & 12 & 13 & $3.1 \%$ & $14.2(6.69)$ & 1.86 \\
\hline Patient-level & 12 & 13 & & & \\
\hline Summary-level & 0 & 0 & & & \\
\hline \multicolumn{6}{|c|}{ Antibacterials for systemic use } \\
\hline \multicolumn{6}{|l|}{ Moxifloxacin } \\
\hline Total & 10 & 10 & $1.7 \%$ & $16.2(8.6)$ & 2.73 \\
\hline Patient-level & 10 & 10 & & & \\
\hline Summary-level & 0 & 0 & & & \\
\hline
\end{tabular}




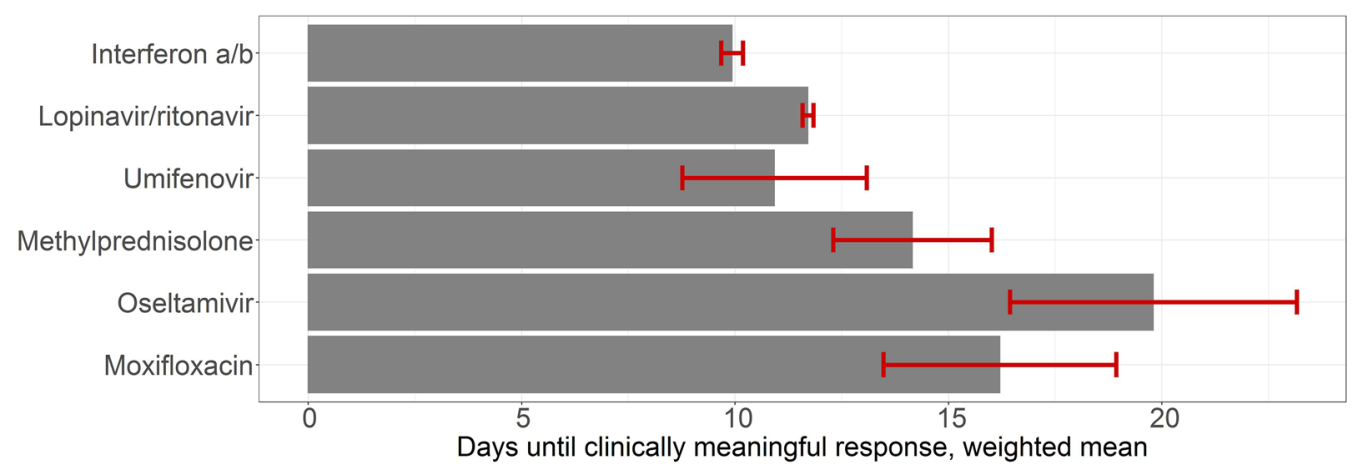

Fig. 3 Mean weighted time to clinically meaningful response associated with the most frequently used drugs. Clinically meaningful response was calculated as the duration from drug start until the earliest of authorreported resolution of symptoms or hospital discharge. Data on drugs with response times available from at least ten studies are included. A mean and standard deviation was imputed from summary-level reports with median

developed and developing countries. Drug repurposing is the fastest route toward an effective and accessible treatment against COVID-19 before a vaccine is available. A previously unquantified but large number of treatments have been tried off-label or experimentally. To date, only small case reports and single-center studies have reported treatments and data on their potential effectiveness. Some of these publications have received more attention than others leading to further use. It is important to systematically evaluate all previously used treatments to avoid missing effective options. In this systematic review, we identified 115 reported treatments that have been used off-label or experimentally to treat COVID-19; we report an initial assessment of associations with clinically meaningful response. Unsurprisingly, antivirals were the most frequently administered class of treatments. Combination lopinavir/ritonavir and interferon- $\alpha / \beta$ were the most frequent treatments given to all patients. Given the limited data and the fact that drugs are often given concurrently or sequentially, we did not seek to compare drugs; however, lopinavir/ritonavir and interferon- $\alpha / \beta$, which had the most of data, were each associated with average TCMR of $<2$ weeks. (interquartile range), and a weighted mean was calculated from available data. Drugs may have been used alone or concurrently with others. TCMR observations were available for $<15$ patients for oseltamivir, methylprednisolone, moxifloxacin, and umifenovir

These data can be used to prioritize promising treatments for randomized controlled trials. Given that the natural history of COVID-19 is complete resolution in most patients, it is essential that prospective, randomly assigned control groups are used to compare with interventional groups. Furthermore, this study can inform public health organizations, governments, and treating physicians about treatments that have been used and could be considered in future patients, considering the current absence of randomized controlled trial data. Many of the 76 regimens proposed by the World Health Organization for COVID-19 treatment in February 2020, as well as proposed in Chinese governmental guidelines, include treatments found in this study [3, 5]. These drugs were likely often given because they were included in these guidelines. Also, the current case fatality rate of COVID-19 is only interpretable in the context of the medical care and treatments provided to patients to date. Some of the most frequently administered treatments in this study could potentially serve as a starting point for a list of essential medicines for resource-limited regions. Lastly, there are a number of high throughput drug screening efforts underway to identify existing drugs that may have activity against SARS-CoV-2. This 


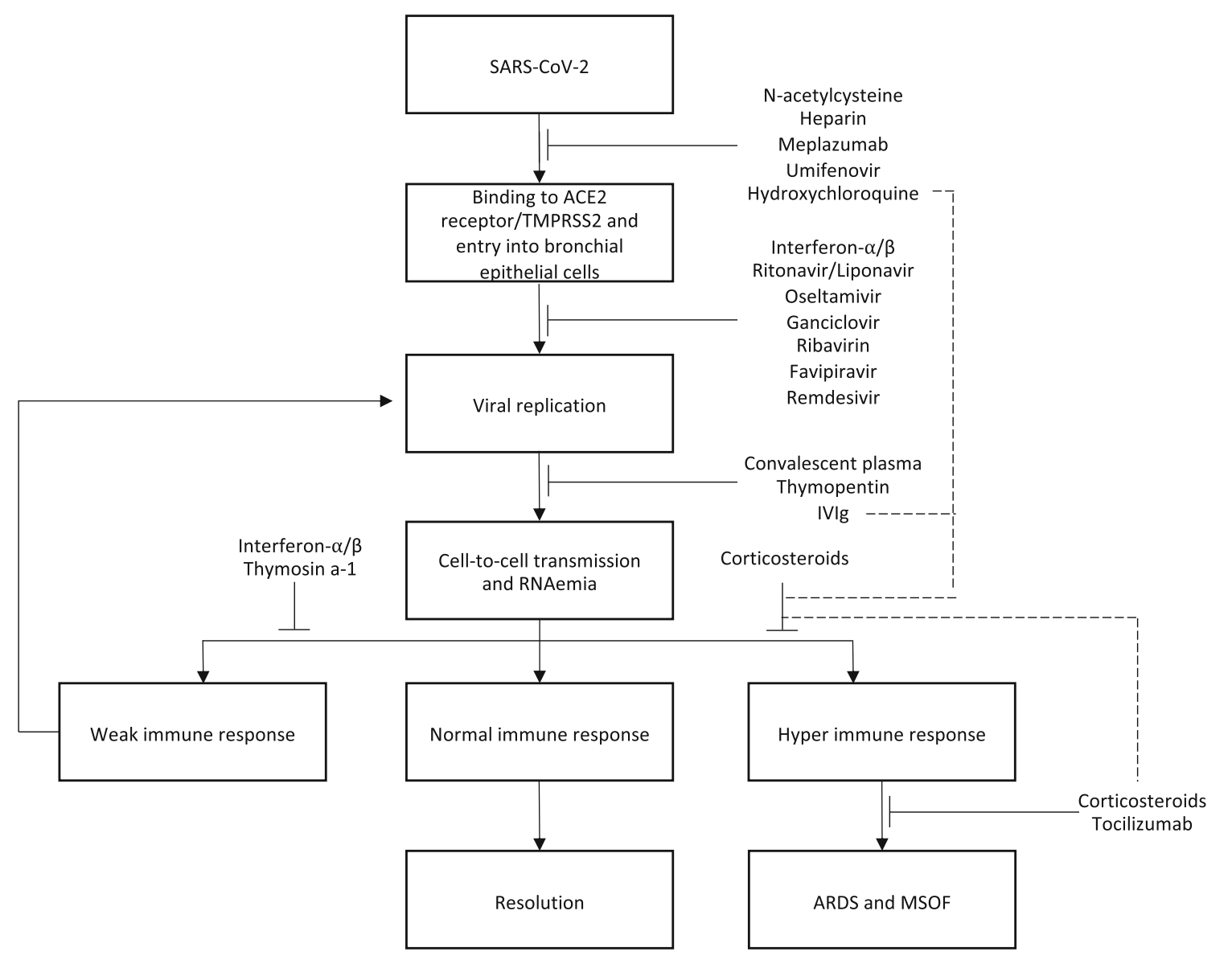

Fig. 4 Potential mechanisms of treatments used to date against COVID-19. Treatments given to patients in this study may be acting through one or more of the following mechanisms or they may also have had no effect: (1) limiting entry into ciliated bronchial epithelial cells $(N$ acetylcysteine, heparin, meplazumab, umifenovir, hydroxychloroquine), (2) inhibiting viral replication (interferon$\alpha / \beta$, ritonavir/lopinavir, oseltamivir, ganciclovir, ribavirin, favipiravir, remdesivir, danoprevir), (3) preventing viral dissemination via antibody-mediated neutralization by increasing SARS-CoV-2-specific antibodies (convalescent plasma) or non-specific antibodies (IVIg, thymopentin), (4) strengthening a weakened immune response with immunostimulants (interferon- $\alpha / \beta$, thymosin- $\alpha-1$ ), (5) preventing a hyper-immune response with immunosuppressants (corticosteroids, hydroxychloroquine, IVIg), or (6) controlling a hyper-immune response (corticosteroids,

study provides information on drugs currently in frequent use.

The treatments that have received the most attention to date include hydroxychloroquine, tocilizumab). Antibiotics such as azithromycin, moxifloxacin, ceftriaxone, and cefoperazone were used more than 25 times but the potential mechanism of action is unknown. These drugs may be acting by preventing secondary infections, controlling inflammation, modulating the microbiome, or directly having an anti-viral effect; they may also have had no effect. A number of treatments also administered in this study support vital organ function, such as bacillis lichenformis (gastrointestinal), antacids (gastrointestinal), continuous renal replacement therapy (kidneys), vasopressors/vasocontrictive agents (cardiovascular), and expectorant and antitussive agents (respiratory). IVIg intravenous immunoglobulin. Dotted lines represent potential secondary mechanisms of action

azithromycin, antivirals used effectively against similar viruses (SARS, MERS, influenza), convalescent plasma, and cytokine storm-directed therapies. In our systematic review, 
hydroxychloroquine was used 114 times. These patients are from a small case series and two large observational studies, which did not provide enough information to calculate a TCMR. Hydroxychloroquine is believed to increase the endosomal $\mathrm{pH}$ needed for virus-cell fusion, interfere with glycosylation of the ACE2 receptor, and modulate the immune response [12]. Data published after the end date of this systematic literature review have revealed notable discrepancies with studies reporting positive outcomes, null results, and potential harmful side effects [13-15]. Ritonavir/lopinavir, administered 2000 times in this study, is a protease inhibitor approved for HIV that has demonstrated activity against MERS and SARS $[16,17]$. Despite its frequent use, one randomized controlled trial included in this study reported no benefit beyond standard of care. However, the study began administration > 10 days into the disease course, so it is still being studied earlier in disease course [18]. Interferon, the second-most frequently administered agent in this study, is a key anti-viral cytokine produced by the host immune system that can inhibit coronavirus replication and boost the immune response [19-21]. It was shown to be effective against SARS-CoV and MERS-CoV $[22,23]$. Oseltamivir was also used frequently in this study, though the primary intent was likely to prevent concomitant influenza infection and it does not seem to be a promising treatment approach. Remdesivir, a nucleoside inhibitor not yet approved for any indication, has demonstrated positive in vitro activity; it was used in a small number of cases in this study [12]. Since completion of this systematic review, a larger open-label compassionate use study and a randomized controlled trial have been published; results from another large randomized control trial were also announced but the paper has not undergone peer review. The compassionate use study provided promising data but did not have a control arm [24]. The published randomized controlled trial did not achieve the primary end point of the study [25], but the other randomized controlled trial was reported to have achieved the primary efficacy end point. Umifenovir, approved for influenza in China and Russia, demonstrated a TCMR of 10.9 (7.78) days in this study, though the sample size was low. A study of 67 patients revealed decreased mortality and improved discharge in patients treated with umifenovir [26]. Interestingly, a randomized controlled trial demonstrated greater clinical improvement in favipiravirtreated patients than umifenovir among moderately ill patients [27]. Convalescent plasma was only given in 12 cases, but it was used previously to treat MERS and SARS, and a number of studies are underway [28-30].

Similar cytokine storm disorders, such as idiopathic multicentric Castleman disease (iMCD), hemophagocytic lymphohistiocytosis, and chimeric antigen receptor $\mathrm{T}$ cell (CART) therapy, are treated by targeting interleukin- 6 (IL-6), IL-1, JAK/STAT, NFkB, mTOR, and NFAT. Given the overlap with these cytokine storm disorders, drugs such as siltuximab, anakinra, corticosteroids, and tocilizumab may be effective for controlling the COVID-19-related cytokine storm [7]. Corticosteroids were administered to over one-fourth of all patients $(N=2392)$ in this study. To date, there have been significant discrepancies between anecdotal reports of corticosteroids helping to improve respiratory function in patients experiencing COVID-19 cytokine storms and recommendations from public health organizations. In fact, public health organizations have recommended against corticosteroids for COVID-19 unless indicated for other conditions [3, 31, 32]. Only $3.1 \%$ of all patients who were administered corticosteroids had sufficient data to calculate a TCMR. Further study is needed. Tocilizumab, which blocks the receptor for IL-6 and is effective at abrogating the cytokine storms in iMCD and CART, has also been anecdotally reported to be effective in critically ill patients. Only 22 patients in our study received tocilizumab. Data from randomized controlled trials are urgently needed and should be available soon. The potential benefits for these drugs to control or prevent a hyper-immune response must be weighed against the risk of accelerating disease progression by suppressing the immune response. There are also unanticipated effects when treatments are deployed against novel diseases, such as the high incidence of venous thromboembolism with intravenous 
immunoglobulin during the 2003 SARS epidemic [33-35].

This study provides several other broad insights into COVID-19. We observed a 55\%-to$45 \%$ male-to-female ratio in these moderate-tosevere COVID-19 cases. A similar pattern was observed for SARS-CoV and MERS-CoV and suspected to be related to protection from sex hormones or differences in the burden of chronic diseases [36-43]. The average age of 44.4 years is younger than in many reports. This may be due to younger patients being more likely to survive a severe presentation and thus more likely to be written up as a case report. Pharmaceutical and traditional Chinese treatments were reported in these publications $[44,45]$. We found that drugs classified as herbal and traditional medicine were used in 693 patients (7.6\%).

This systematic review has several important limitations. In view of the limited number of randomized controlled trials, all papers published in PubMed or archives were included. Therefore, there are case reports and case series with considerably lower data quality standards than randomized controlled trials. From our standpoint, case reports present substantial data quality limitations but they often provide clear information on what treatments were administered and the day of clinically meaningful response, which were the two primary objectives of this study. Furthermore, we felt that data-archived articles about patient characteristics and treatments were important to include and unlikely to change during the peer-review process. Given the current crisis, we chose to enlist a large number of extractors to review the 2706 papers. To improve data quality, a medical doctor or medical student re-reviewed every single extracted case, and any discrepancies were resolved by consensus among extractor \#1, extractor \#2, an independent reviewer (JSK), senior statistician (SKP), and principal investigator (DCF). This sample set is highly skewed toward hospitalized patients and thus is not likely representative of all COVID-19 patients, and publication bias is likely. Specifically, physicians tend to write up cases where patients have positive outcomes. These papers also tend to be published faster than negative results.
Given the proximity to the emergence of this pandemic and the desire for effective solutions, we expect that there is significant publication bias among the articles in this study. The inclusion of not-yet-published studies, such as the studies we included from archives, within a systematic review can help to reduce publication bias, providing a better estimate of effectiveness or association. Furthermore, the primary objective of this study is to inventory and quantify the various treatments used for COVID-19, which is unlikely to go unreported within a given study. For our secondary objective of assessing the TCMR, there is a risk of bias regarding missing data, measurement of outcomes, and selective outcome reporting. We attempted to mitigate these biases by using a standardized definition of TCMR that overcomes heterogeneity of reported outcomes. However, we did not consider concurrent or sequential drug use when associating TCMR. When sufficient data were not available to determine TCMR for a given study, those cases were not included in the TCMR analysis. Only three articles in this study were randomized controlled trials, so risk of biases related to randomization, allocation, and blinding are not applicable in nearly all studies. However, biased participant selection and misclassification of interventions may influence results in nonrandomized studies. Physicians with resources to write articles may have more resources available to treat their patients. Mortality was not assessed as the majority of publications did not report survival and many patients were still hospitalized at the time of publication. Furthermore, we could not control for the natural history or severity of the disease. These data mostly come from treatment of patients in China, where SARS-CoV-2 emerged, and treatment strategies may differ in other regions. Finally, some studies were extracted through translations instead of the full original text. Despite these limitations, this systematic review provides the first broad overview of treatments tried against COVID-19 and insights that can inform practicing public health organizations, clinicians, and clinical trial prioritization. 


\section{CONCLUSION}

COVID-19 represents the largest global pandemic and widespread threat to human health in decades. Fortunately, thousands of drugs are available for other indications and can be used off-label immediately. Unfortunately, no central register of all treatments used for COVID-19 exists, so limited data exist on treatment use and activity. Therefore, physicians do not have information on potentially promising treatments and biopharmaceutical companies must make decisions about clinical trials with limited data. We present the first systematic review of treatments used against COVID-19. While the data contained in this study suggest that some drugs may have an effect on treating COVID-19, we strongly encourage clinicians to prescribe treatments based on the results of well-designed randomized controlled trials. This study should serve as an inventory of treatments administered to COVID-19 patients and assist with prioritizing drugs for well-designed randomized controlled trials, having the potential to improve clinical outcomes and reduce the strain on inpatient care in the current pandemic. The importance of these data, heterogeneity of the data, and the time and resources required to perform this study emphasize the urgent need for systematic data collection on off-label and experimental treatments against COVID-19 as well as randomized controlled trials of promising agents. Learning from this experience to inform future pandemics and aid in the discovery of effective treatments for the approximately 7000 diseases without treatments is critically important.

\section{ACKNOWLEDGEMENTS}

We thank Anna Wing, Michael A. Mayer, Megan Fisher, James Germi, Ashwin Amurthur, Eric Rodriguez-Lopez, Bruna Martins, Stephen Bambury, Karen Gunderson, Nick Goodyear, and Cornelia A. Keyser for their contributions to this study. We also thank the physicians, researchers, and patients who contributed their data to help future patients.
Funding. No funding or sponsorship was received for this study or publication of this article. The Rapid Service Fee was funded by the authors. All authors had full access to all the data in the study and had final responsibility for the decision to submit for publication.

Authorship. All named authors meet the International Committee of Medical Journal Editors (ICMJE) criteria for authorship for this article, take responsibility for the integrity of the work as a whole, and have given their approval for this version to be published.

Authorship Contributions. Joseph J. Kakkis, Mileva Repasky, Anne Taylor, Alexander Beschloss, Laura Hernandez-Miyares, Beatrice Go, Vivek Nimgaonkar, Madison S. McCarthy, Casey J. Kim, Ruth-Anne Langan Pai, Sarah Frankl, Philip Angelides, Joanna Jiang, Rozena Rasheed, Erin Napier, and Duncan Mackay reviewed and extracted data from articles and reviewed and revised the manuscript. Alexander Gorzewski, Mark-Avery Tamakloe, and Victoria Powers reviewed and extracted data from articles, performed a re-review of every previously extracted articles, and reviewed and revised the manuscript. Johnson S. Khor did the literature search, reviewed and extracted data from articles, performed data quality queries, analyzed data, and reviewed and revised the manuscript. Sheila K. Pierson planned the study, analyzed data, and reviewed and revised the manuscript. David C. Fajgenbaum planned the study and wrote the manuscript.

Disclosures. David C. Fajgenbaum, Johnson S. Khor, Alexander Gorzewski, Mark-Avery Tamakloe, Victoria Powers, Joseph J. Kakkis, Mileva Repasky, Anne Taylor, Alexander Beschloss, Laura Hernandez-Miyares, Beatrice Go, Vivek Nimgaonkar, Madison S. McCarthy, Casey J. Kim, Ruth-Anne Langan Pai, Sarah Frankl, Philip Angelides, Joanna Jiang, Rozena Rasheed, Erin Napier, Duncan Mackay, and Sheila K. Pierson declare no competing interests.

Compliance with Ethical Guidelines. This article is based on previously conducted studies 
and does not contain any studies with human participants or animals performed by any of the authors.

Open Access. This article is licensed under a Creative Commons Attribution-NonCommercial 4.0 International License, which permits any non-commercial use, sharing, adaptation, distribution and reproduction in any medium or format, as long as you give appropriate credit to the original author(s) and the source, provide a link to the Creative Commons licence, and indicate if changes were made. The images or other third party material in this article are included in the article's Creative Commons licence, unless indicated otherwise in a credit line to the material. If material is not included in the article's Creative Commons licence and your intended use is not permitted by statutory regulation or exceeds the permitted use, you will need to obtain permission directly from the copyright holder. To view a copy of this licence, visit http://creativecommons.org/licenses/bync/4.0/.

\section{REFERENCES}

1. Dong E, Du H, Gardner L. An interactive web-based dashboard to track COVID-19 in real time. London: Lancet Publishing Group; 2020.

2. Chen N, Zhou M, Dong X, Qu J, Gong F, Han Y, Qiu Y, Wang J, Liu Y, Wei Y, Xia J, Yu T, Zhang X, Zhang L. Epidemiological and clinical characteristics of 99 cases of 2019 novel coronavirus pneumonia in Wuhan, China: a descriptive study. Lancet. 2020;395(10223):507-13.

3. Coronavirus disease (COVID-2019) R\&D. 2020. https://www.who.int/blueprint/priority-diseases/ key-action/novel-coronavirus/en/. Accessed 21 Apr 2020.

4. Moher D, Liberati A, Tetzlaff J, Altman DG. Preferred reporting items for systematic reviews and meta-analyses: the PRISMA statement. PLoS Med. 2009;6(7):e1000097.

5. Wan X, Wang W, Liu J, Tong T. Estimating the sample mean and standard deviation from the sample size, median, range and/or interquartile range. BMC Med Res Methodol. 2014;14:135.
6. Dong L, Hu S, Gao J. Discovering drugs to treat coronavirus disease 2019 (COVID-19). Drug Discov Ther. 2020;14(1):58-60.

7. Lan J, Ge J, Yu J, Shan S, Zhou H, Fan S, Zhang Q, Shi X, Wang Q, Zhang L, Wang X. Structure of the SARS-CoV-2 spike receptor-binding domain bound to the ACE2 receptor. Nature. 2020;30(3):1-9.

8. Mehta P, McAuley DF, Brown M, Sanchez E, Tattersall RS, Manson JJ. COVID-19: consider cytokine storm syndromes and immunosuppression, vol. 395. London: Lancet Publishing Group; 2020. p. 1033-1034.

9. Duchateau J, Delespesse G, Bolla K. Phase variation in the modulation of the human immune response. Immunol Today. 1983;4(8):213-4.

10. Duchateau J, Servais G, Vreyens R, Delespesse G, Bolla K. Modulation of immune response in aged humans through different administration modes of thymopentin. Survey Immunol Res. 1985;4(1 Supplement):94-101.

11. Gao Z-C, Zhu J-H, Sun Y, Ding X, Ma J-S, Cui Y-X, $\mathrm{Du} X-\mathrm{K}, \mathrm{Gao} \mathrm{T}, \mathrm{He} \mathrm{Q}-\mathrm{Y}$. Clinical investigation of outbreak of nosocomial severe acute respiratory syndrome. Zhongguo Wei Zhong Bing Ji Jiu Yi Xue. 2003;15(6):332-5.

12. Kumar V, Jung Y-S, Liang P-H. Anti-SARS coronavirus agents: a patent review (2008-present). Expert Opin Ther Patents. 2013;23(10):1337-488.

13. Chen Z, Hu J, Zhang Z, Jiang S, Han S, Yan D, Zhuang $\mathrm{R}, \mathrm{Hu} \mathrm{B}$, Zhang Z. Efficacy of hydroxychloroquine in patients with COVID-19: results of a randomized clinical trial. Science. 2020;7: 20040758.

14. Grein J, Ohmagari N, Shin D, Diaz G, Asperges E, Castagna A, Feldt T, Green G, Green ML, Lescure F-X, Nicastri E, Oda R, Yo K, Quiros-Roldan E, Studemeister A, Redinski J, Ahmed S, Bernett J, Chelliah D, Chen D, Chihara S, Cohen SH, Cunningham J, D'Arminio Monforte A, Ismail S, Kato H, Lapadula G, L'Her E, Maeno T, Majumder S, Massari M, Mora-Rillo M, Mutoh Y, Nguyen D, Verweij E, Zoufaly A, Osinusi AO, DeZure A, Zhao Y, Zhong L, Chokkalingam A, Elboudwarej E, Telep L, Timbs L, Henne I, Sellers S, Cao H, Tan SK, Winterbourne L, Desai P, Mera R, Gaggar A, Myers RP, Brainard DM, Childs R, Flanigan T. Compassionate use of remdesivir for patients with severe covid-19. N Engl J Med. 2020. https://doi.org/10.1056/ NEJMoa2007016.

15. Mercuro NJ, Yen CF, Shim DJ, Maher TR, McCoy CM, Zimetbaum PJ, Gold HS. Risk of QT interval prolongation associated with use of hydroxychloroquine with or without concomitant 
azithromycin among hospitalized patients testing positive for coronavirus disease 2019 (COVID-19). JAMA Cardiol. 2020;1:5.

16. Turner RB, Felton A, Kosak K, Kelsey DK, Meschievitz CK. Prevention of experimental coronavirus colds with intranasal (1-2b interferon). J Infect Dis. 1986;154(3):443-7.

17. Morgenstern B, Michaelis M, Baer PC, Doerr HW, Cinatl J. Ribavirin and interferon- $\beta$ synergistically inhibit SARS-associated coronavirus replication in animal and human cell lines. Biochem Biophysi Res Commun. 2005;326(4):905-8.

18. Loutfy MR, Blatt LM, Siminovitch KA, Ward S, Wolff B, Lho H, Pham DH, Deif H, LaMere EA, Chang M, Kain KC, Farcas GA, Ferguson P, Latchford M, Levy G, Dennis JW, Lai EK, Fish EN. Interferon Alfacon-1 plus corticosteroids in severe acute respiratory syndrome: a preliminary study. J Am Med Assoc. 2003;290(24):3222-8.

19. Wang M, Cao R, Zhang L, Yang X, Liu J, Xu M, Shi $\mathrm{Z}$, $\mathrm{Hu} \mathrm{Z}$, Zhong W, Xiao G. Remdesivir and chloroquine effectively inhibit the recently emerged novel coronavirus (2019-nCoV) in vitro. Springer Nat. 2020;30:269-71.

20. Kim UJ, Won EJ, Kee SJ, Jung SI, Jang HC. Combination therapy with lopinavir/ritonavir, ribavirin and interferon-a for Middle East respiratory syndrome. Antiviral Therapy. 2016;21(5):455-9.

21. Chu CM, Cheng VC, Hung IF, Wong MM, Chan KH, Chan KS, Kao RY, Poon LL, Wong CL, Guan Y, Peiris JS, Yuen KY. Role of lopinavir/ritonavir in the treatment of SARS: Initial virological and clinical findings. Thorax. 2004;59(3):252-6.

22. Cao B, Wang Y, Wen D, Liu W, Wang J, Fan G, Ruan L, Song B, Cai Y, Wei M, Li X, Xia J, Chen N, Xiang J, Yu T, Bai T, Xie X, Zhang L, Li C, Yuan Y, Chen H, Li H, Huang H, Tu S, Gong F, Liu Y, Wei Y, Dong C, Zhou F, Gu X, Xu J, Liu Z, Zhang Y, Li H, Shang L, Wang K, Li K, Zhou X, Dong X, Qu Z, Lu S, Hu X, Ruan S, Luo S, Wu J, Peng L, Cheng F, Pan L, Zou J, Jia C, Wang J, Liu X, Wang S, Wu X, Ge Q, He J, Zhan H, Qiu F, Guo L, Huang C, Jaki T, Hayden FG, Horby PW, Zhang D, Wang C. A trial of lopinavirritonavir in adults hospitalized with severe Covid19. N Engl J Med. 2020;18:3.

23. Pei J, Sekellick MJ, Marcus PI, Choi IS, Collisson EW. Chicken interferon type I inhibits infectious bronchitis virus replication and associated respiratory illness. J Interf Cytokine Res. 2001;21(12): 1071-7.

24. Million M, Lagier J-C, Gautret $\mathrm{P}$, Colson $\mathrm{P}$, Fournier P-E, Amrane S, Hocquart M, Mailhe M, EstevesVieira V, Doudier B, Aubry C, Correard F, Giraud-
Gatineau A, Roussel Y, Berenger C, Cassir N, Seng P, Zandotti C, Dhiver C, Ravaux I, Tomei C, Eldin C, Tissot-Dupont H, Honoré S, Stein A, Jacquier A, Deharo J-C, Chabrière E, Levasseur A, Fenollar F, Rolain J-M, Obadia Y, Brouqui P, Drancourt M, La Scola B, Parola P, Raoult D. Early treatment of COVID-19 patients with hydroxychloroquine and azithromycin: a retrospective analysis of 1061 cases in Marseille, France. Travel Med Infect Dis. 2020. https://doi.org/10.1016/j.tmaid.2020.101738.

25. Wang Y, Zhang D, Du G, Du R, Zhao J, Jin Y, Fu S, Gao L, Cheng Z, Lu Q, Hu Y, Luo G, Wang K, Lu Y, Li H, Wang S, Ruan S, Yang C, Mei C, Wang Y, Ding D, Wu F, Tang X, Ye X, Ye Y, Liu B, Yang J, Yin W, Wang A, Fan G, Zhou F, Liu Z, Gu X, Xu J, Shang L, Zhang Y, Cao L, Guo T, Wan Y, Qin H, Jiang Y, Jaki T, Hayden FG, Horby PW, Cao B, Wang C. Remdesivir in adults with severe COVID-19: a randomised, double-blind, placebo-controlled, multicentre trial. Lancet 2020;395(10236):1569-78.

26. Wang Z, Yang B, Li Q, Wen L, Zhang R. Clinical features of 69 cases with coronavirus disease 2019 in Wuhan, China. Clin Infect Diseases. 2020.

27. Chen C, Huang J, Cheng Z, Wu J, Chen S, Zhang Y, Chen B, Lu M, Luo Y, Zhang J, Yin P, Wang X. Favipiravir versus arbidol for COVID-19: a randomized clinical trial. medRxiv. 2020; 20037432.

28. Mustafa S, Balkhy H, Gabere MN. Current treatment options and the role of peptides as potential therapeutic components for Middle East Respiratory Syndrome (MERS): a review, vol. 11. New York: Elsevier Ltd; 2018. p. 9-17.

29. Arabi $Y$, Balkhy H, Hajeer AH, Bouchama A, Hayden FG, Al-Omari A, Al-Hameed FM, Taha Y, Shindo N, Whitehead J, Merson L, AlJohani S, Al-Khairy K, Carson G, Luke TC, Hensley L, Al-Dawood A, AlQahtani S, Modjarrad K, Sadat M, Rohde G, Leport C, Fowler R. Feasibility, safety, clinical, and laboratory effects of convalescent plasma therapy for patients with Middle East respiratory syndrome coronavirus infection: a study protocol. SpringerPlus. $2015 ; 4(1): 1-8$.

30. Cheng Y, Wong R, Soo YO, Wong WS, Lee CK, Ng $\mathrm{MH}$, Chan P, Wong KC, Leung CB, Cheng G. Use of convalescent plasma therapy in SARS patients in Hong Kong. Eur J Clin Microbiol Infect Diseases. 2005;24(1):44-6.

31. Cinatl J, Morgenstern B, Bauer G, Chandra P, Rabenau H, Doerr HW. Glycyrrhizin, an active component of liquorice roots, and replication of SARS-associated coronavirus. Lancet. 2003;361(9374):2045-6.

32. Russell CD, Millar JE, Baillie JK. Clinical evidence does not support corticosteroid treatment for 
2019-nCoV lung injury, vol. 395. London: Lancet Publishing Group; 2020. p. 473-475.

33. Soo YO, Cheng Y, Wong R, Hui DS, Lee CK, Tsang $\mathrm{KK}, \mathrm{Ng} \mathrm{MH}$, Chan P, Cheng G, Sung JJ. Retrospective comparison of convalescent plasma with continuing high-dose methylprednisolone treatment in SARS patients. Clin Microbiol Infect. 2004;10(7): 676-8.

34. Zhang L, Liu Y. Potential interventions for novel coronavirus in China: a systematic review, vol. 92. New York: Wiley; 2020. p. 479-490.

35. Lew TW, Kwek TK, Tai D, Earnest A, Loo S, Singh K, Kwan KM, Chan Y, Yim CF, Bek SL, Kor AC, Yap WS, Chelliah YR, Lai YC, Goh SK. Acute respiratory distress syndrome in critically ill patients with severe acute respiratory syndrome. J Am Med Assoc. 2003;290(3):374-80.

36. Dalakas MC, Clark WM. Strokes, thromboembolic events, and IVIg: rare incidents blemish an excellent safety record, vol. 60. Philadelphia: Lippincott Williams and Wilkins; 2003. p. 1736-1737.

37. Badawi A, Ryoo SG. Prevalence of comorbidities in the Middle East respiratory syndrome coronavirus (MERS-CoV): a systematic review and meta-analysis, vol. 49. New York: Elsevier; 2016. p. 129-133.

38. Channappanavar R, Fett C, Mack M, Ten Eyck PP, Meyerholz DK, Perlman S. Sex-based differences in susceptibility to severe acute respiratory syndrome coronavirus infection. J Immunol. 2017;198(10): 4046-53.

39. Jaillon S, Berthenet K, Garlanda C. Sexual dimorphism in innate immunity, vol. 56. Totowa: Humana Press Inc.; 2019. p. 308-321.
40. Dryden M, Baguneid M, Eckmann C, Corman S, Stephens J, Solem C, Li J, Charbonneau C, BaillonPlot N, Haider S. Pathophysiology and burden of infection in patients with diabetes mellitus and peripheral vascular disease: focus on skin and softtissue infections. Clin Microbiol Infect. 2015;21: S27-S32.

41. Marriott I, Huet-Hudson YM. Sexual dimorphism in innate immune responses to infectious organisms, vol. 34. New York: Springer; 2006. p. 177-192.

42. Karlberg J, Chong DSY, Lai WYY. Do men have a higher case fatality rate of severe acute respiratory syndrome than women do? Am J Epidemiol Hopkins Bloomberg School Public Health All Rights Reserved. 2004;159(3):229-31.

43. Leong H-N, Earnest A, Lim H-H, Chin C-F, Tan CS, Puhaindran ME, Tan AC, Chen MI, Leo Y-S. SARS in Singapore-predictors of Disease Severity. Ann Acad Med Singapore. 2006;35(5):326-31.

44. Alghamdi I, Hussain I, Alghamdi M, Almalki S, Alghamdi M, Elsheemy M. The pattern of Middle East respiratory syndrome coronavirus in Saudi Arabia: a descriptive epidemiological analysis of data from the Saudi Ministry of Health. Int J General Med. 2014;7:417.

45. Chen F, Chan KH, Jiang Y, Kao RY, Lu HT, Fan KW, Cheng VC, Tsui WH, Hung IF, Lee TS, Guan Y, Peiris JS, Yuen KY. In vitro susceptibility of ten clinical isolates of SARS coronavirus to selected antiviral compounds. J Clin Virol. 2004;31(1): 69-75. 